\title{
Isolated Orbital Fractures Are Severe Among Geriatric Patients
}

\section{Toivari, Miika}

2018-02

Toivari , M , Suominen , A L , Apajalahti , S , Lindqvist , C , Snäll , J \& Thoren , H 2018 , ' Isolated Orbital Fractures Are Severe Among Geriatric Patients ' , Journal of Oral and Maxillofacial Surgery, vol. 76 , no. 2 , pp. 388-395 . https://doi.org/10.1016/j.joms.2017.09.019

http://hdl.handle.net/10138/300068

https://doi.org/10.1016/j.joms.2017.09.019

publishedVersion

Downloaded from Helda, University of Helsinki institutional repository.

This is an electronic reprint of the original article.

This reprint may differ from the original in pagination and typographic detail.

Please cite the original version. 


\title{
Isolated Orbital Fractures Are Severe Among Geriatric Patients
}

\author{
Miika Toivari, DDS, * Anna Liisa Suominen, DDS, PbD, MSc, $\dagger$ \\ Satu Apajalabti, DDS, PbD, $\ddagger$ Christian Lindqvist, $M D, D D S, P b D, \S$ \\ Johanna Snäll, DDS, MD, PbD, // and Hanna Thorén, MD, DDS, PhD đ
}

\begin{abstract}
Purpose: The purpose of the present study was to clarify the reasons for, types of, and degree of involvement of the orbital wall and the severity of orbital fractures in geriatric patients and to compare the differences between geriatric and younger adult patients.
\end{abstract}

Materials and Methods: A retrospective case-control study of geriatric patients aged at least 65 years $(n=72)$ and younger controls aged 20 to 50 years $(n=58)$ with a diagnosis of a unilateral isolated orbital fracture was designed and implemented. The main exposure was age, the primary outcome was the isolated orbital fracture type, and the secondary outcomes were the associated orbital zones, fracture area $\left(\mathrm{cm}^{2}\right)$, degree of dislocation ( $\mathrm{mm}$ ), involvement of anatomic landmarks, diplopia, altered ocular position, restricted eye movement, and ocular injuries. The confounding variables were gender, trauma mechanism, and alcohol abuse. The statistical methods included $\chi^{2}$ tests and logistic regression analyses.

Results: Among the geriatric patients, the great majority of isolated orbital fractures had been caused by falls $(66.7 \% ; P<.001)$. Geriatric orbital fractures were significantly more often extensive $\left(2 \mathrm{~cm}^{2}\right.$ or larger; $P=.045)$ and associated with the middle-posterior orbital third $(P=.032)$. In the logistic regression analyses, the elderly had a 2.2-fold greater risk of fractures of the middle-posterior orbital third and a 2.3 -fold greater risk of extensive fractures compared with the younger controls. Ocular injuries were only diagnosed in the geriatric patients (5.6\%).

Conclusions: Falling is the most common mechanism of elderly orbital fractures. Isolated orbital fractures are extensive and mainly affect the globe supporting the middle and posterior parts of the orbital floor among geriatric patients.

(C) 2017 American Association of Oral and Maxillofacial Surgeons

J Oral Maxillofac Surg 76:388-395, 2018

Orbital fractures are among the most common traumatic injuries of the face, ranging from 16 to $32 \%$ of all facial injuries. ${ }^{1,2}$ More recently, studies focusing on geriatric facial traumas have reported that the frequency of orbital fractures is age dependent. In recent reports, orbital fractures have been up to 2.7

\footnotetext{
*Resident, Department of Oral and Maxillofacial Diseases, University of Helsinki and Helsinki University Hospital, Helsinki, Finland.

$\dagger$ Professor, Department of Health, Functional Capacity and Welfare/Department of Environmental Health, National Institute for Health and Welfare, Helsinki/Kuopio, Finland; Department of Oral Public Health, Institute of Dentistry, University of Eastern Finland, Kuopio, Finland; and Department of Oral and Maxillofacial Surgery, Kuopio University Hospital, Kuopio, Finland.

$\ddagger$ Radiologist, HUS Medical Imaging Center, Department of Radiology, University of Helsinki University Hospital, Helsinki, Finland.

$\S$ Professor, Department of Oral and Maxillofacial Diseases, University of Helsinki and Helsinki University Hospital, Helsinki, Finland.

\|Consultant, Department of Oral and Maxillofacial Diseases, University of Helsinki and Helsinki University Hospital, Helsinki, Finland.
} 
times more frequent among the elderly (range 21.4 to 28.2\%) than younger adult patients (range 10.3 to $18.1 \%)^{3,4}$

In addition to frequency, age dependency in the mechanism of the orbital fractures has been revealed in recent studies. In their 2004 analysis of the published data, Cruz and Eichenberger ${ }^{5}$ concluded that the main causes of orbital fractures are motor vehicle accidents (MVAs; range 51.0 to $57.0 \%$ ) and that interpersonal violence (7.3\%) and falls (range 7.1 to 20.3\%) constitute a minor proportion of orbital trauma causes. However, other studies have shown that, especially among the elderly population, up to $43.8 \%$ of orbital fractures are sustained because of falls ${ }^{6}$ and that interpersonal violence among the younger age groups is a much more frequent cause (range 33.8 to $37.8 \%)^{7}$ than was concluded by Cruz and Eichenberger. ${ }^{5}$ Regardless of the different etiologies, the connecting factor is the blunt nature of the mechanism in orbital traumas.

An orbital fracture can be defined as pure (isolated) when the orbital rims, zygomatic-orbital complex, naso-orbitoethmoid complex, and the maxillary Le Fort lines are unaffected. ${ }^{8,9}$ The relevance of orbital fractures lies in whether the trauma results in posttraumatic ocular dysfunction due to an altered ocular position. The most commonly affected site in isolated orbital fractures is the orbital floor (range 40.3 to $97.4 \%),{ }^{10,11}$ which has been shown to relate, in particular, to an altered post-traumatic ocular position. ${ }^{12}$ Unresolved soft tissue entrapment with disabling diplopia, enophthalmos greater than $2 \mathrm{~mm}$, and an extensive $\left(2 \mathrm{~cm}^{2}\right.$ or greater) orbital fracture, which can be considered as signs of a significant orbital fracture, are generally accepted as indications for operative treatment. ${ }^{13,14}$ Moreover, a change in the ocular position and resulting ocular dysfunction can occur; thus, the detection of potential ocular injuries in orbital trauma is the main priority to prevent the loss of vision in the event of an orbital fracture. The fracture depth, penetrating mechanisms, abnormal vision or visual acuity, and an abnormal pupillary reflex have been identified as factors affecting the ocular injury risk in the presence of orbital trauma. ${ }^{15,16}$

According to the published data, geriatric patients sustain orbital fractures more frequently than do younger adults, mainly from falls. However, to the best of our knowledge, no previous studies have compared the clinical and radiologic findings of isolated orbital fractures between elderly and younger adult patients.

The purpose of the present study was to investigate the differences in isolated orbital fractures in geriatric and younger adult patients. The specific aims were to design and implement a case-control study to clarify the reasons for, types of, and degree of involvement of the orbital wall and the severity of isolated orbital fractures in geriatric patients and to compare the clinical and radiologic characteristics of these patients with those of younger controls. The hypotheses were that age and age-related mechanisms would predispose to different types of radiologic findings in orbital fractures and that ocular injuries are common among the elderly.

\section{Materials and Methods}

\section{STUDY DESIGN}

To address the aims of the present research, a retrospective case-control study was designed and implemented. Included were geriatric patients (aged at least 65 years) and younger controls (aged 20 to 50 years) with a diagnosis of a unilateral isolated orbital fracture during the 9-year period from January 1, 2006 through December 31, 2014. An additional inclusion criterion was the availability of computed tomography (CT) scans for evaluation in 3 planes (ie, axial, coronal, and sagittal). Patients whose orbital fracture extended to the orbital rim and those with any other facial fracture were excluded.

\section{STUDY VARIABLES}

The main exposure was age (ie, geriatric patients vs younger adults). The primary outcome variable was the type of orbital fracture. Orbital fractures were classified as 1) an isolated fracture of the orbital floor, 2) an isolated fracture of the medial orbital wall, 3) a combined orbital fracture (ie, floor plus medial or lateral wall, medial plus lateral wall, floor plus medial wall plus roof of orbit), or 4) other (ie, isolated fractures of the orbital roof or lateral wall).

The secondary outcome variables were the associated orbital zones in the anteroposterior direction, fracture area $\left(\mathrm{cm}^{2}\right)$, presence and degree of fracture dislocation $(\mathrm{mm})$, and involvement of relevant anatomic landmarks. The associated zones were classified as follows: zone 1 , anterior orbital third; zone 2 , middle orbital third; and zone 3, posterior orbital third (Fig 1). The fracture area was classified as 1) a fissure, 2) less than $2 \mathrm{~cm}^{2}$ and 3) $2 \mathrm{~cm}^{2}$ or greater. The relevant involved landmarks were classified as the posterior orbital ledge, intraorbital buttress, and inferior orbital fissure (Fig 1). Additional secondary outcome measures included the presence of diplopia, a clinically diagnosed altered ocular position, clinically restricted eye movement, and other clinically or radiologically diagnosed ocular or orbital injuries.

The confounding variables were gender, trauma mechanism, and alcohol abuse. 


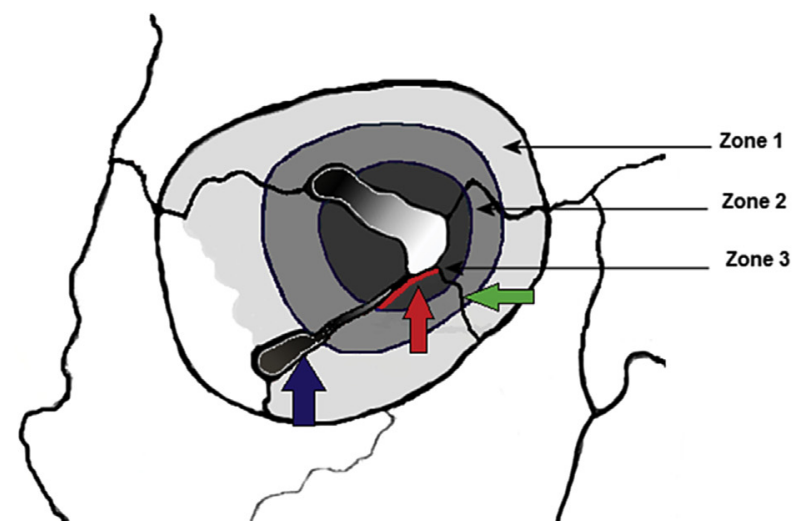

Inferior orbital fissure (blue arrow)

Intraorbital buttress (green arrow)

Posterior ledge (red arrow / red line)

FIGURE 1. Illustration of the orbital thirds and relevant anatomic landmarks.

Toivari et al. Severity of Isolated Orbital Fractures in Geriatric Patients. J Oral Maxillofac Surg 2018.

\section{RADIOLOGIC ANALYSES}

CT imaging was performed using multidetector CT scanners (GE Healthcare, Milwaukee, WI) with a bone algorithm. The data were reformatted into axial, coronal, and sagittal images with a thickness of 1.0, 1.5 , or $2.0 \mathrm{~mm}$. The CT measurements were performed independently by 2 of us (M.T., C.L.). In the case of disagreement regarding the degree of dislocation or fracture area, the lower value was chosen for analysis. The involvement of relevant intraorbital landmarks was only registered in the case of agreement.

\section{STATISTICAL ANALYSIS}

For the statistical analysis, the associated zones were combined as 1) fractures that only associated the anterior with or without the middle orbital third (ie, zone 1 and/or zone 2), and 2) fractures that associated the middle with or without the posterior orbital third (ie, zone 3 plus zone 2 and/or zone 1). $\chi^{2}$ Tests were used to analyze the statistical significance of differences between the age groups in the outcomes and confounding variables and the primary outcome with the confounding variables. Logistic regression analysis was performed to examine the associations of the exposure with the primary outcome (orbital fracture type dichotomized as 1 [isolated fracture of the orbital floor] or 0 [other]) and the 2 secondary outcomes (associated zone, dichotomized as 1 [fracture in posterior third alone or combined with others] or 0 [no posterior fracture]; and fracture area without fissure fracture, dichotomized as $1\left[2 \mathrm{~cm}^{2}\right.$ or more $]$ or 0 [less than $\left.2 \mathrm{~cm}^{2}\right]$ ).

\section{ETHICAL CONSIDERATIONS}

The internal review board of the musculoskeletal surgery division, Helsinki University Hospital (Helsinki, Finland), approved the present study.

\section{Results}

A total of 72 geriatric patients (age 65 years or older) and 58 younger controls (age 20 to 50 years) were identified for the analyses. The associations between gender, trauma mechanism, and alcohol abuse and age group are listed in Table 1 . The proportion of female patients was significantly greater among the geriatric patients $(66.7 \%)$, and the proportion of male patients was greater among the younger adult patients $(65.5 \% ; P<.001)$. A fall on the ground was by far the most common trauma mechanism for isolated orbital fractures in the geriatric group (79.2\%). In contrast, assault was the dominant cause among the younger control group $(67.2 \% ; P<.001)$. The younger controls had significantly more often been affected by alcohol (37.3\%) compared with the elderly $(15.3 \% ; P=.003)$.

The associations between gender, trauma mechanism, and alcohol abuse and the type of orbital fracture are presented in Table 2. The trauma mechanism was the only significant predictor of the type of fracture $(P=.049)$. The frequency of isolated fractures of the floor was greatest when associated with a hit by a blunt object (100.0\%), MVAs (75.0\%), assaults (66.7\%), and falling on the ground (65.0\%). Combined injuries were equally common for the injuries associated with sports $(25.0 \%)$, assault (23.8\%), and falls on the ground (23.3\%). Although the difference was not statistically different, isolated fractures of the floor were more common among female patients (72.1\%) and combined injuries were more common among male patients $(27.4 \% ; P=.139)$, and alcohol abuse was mainly related to isolated fractures of the floor (63.6\%; $P=.949)$.

The associations between age groups and the radiologic and clinical outcome variables are presented in Table 3 . Zones 1 to 3, 2 plus 3, and 3 were significantly more frequently involved in the geriatric patients $(63.9 \%)$ than in the younger controls (46.6\%; 


\begin{tabular}{|c|c|c|c|}
\hline Variable & $\begin{array}{c}\text { Geriatric } \\
\text { Patients } \\
(n=72)\end{array}$ & $\begin{array}{l}\text { Younger } \\
\text { Controls } \\
(n=58)\end{array}$ & $P$ Value \\
\hline Gender & & & $<.001$ \\
\hline Female & $48(66.7)$ & $20(34.5)$ & \\
\hline Male & $24(33.3)$ & $38(65.5)$ & \\
\hline Trauma mechanism & & & $<.001$ \\
\hline Fall on the ground & $57(79.2)$ & $3(5.2)$ & \\
\hline Unknown & $4(5.6)$ & $1(1.7)$ & \\
\hline MVA & $3(4.2)$ & $5(8.6)$ & \\
\hline Assault & $3(4.2)$ & $39(67.2)$ & \\
\hline Bicycle & $2(2.7)$ & $3(5.2)$ & \\
\hline Fall from height & $2(2.7)$ & $3(5.2)$ & \\
\hline Hit by a blunt object & $1(1.4)$ & $0(0)$ & \\
\hline Sport & $0(0)$ & $4(6.9)$ & \\
\hline Alcohol abuse & $11(15.3)$ & $22(37.9)$ & .003 \\
\hline
\end{tabular}

Data presented as $\mathrm{n}(\%)$.

Abbreviation: MVA, motor vehicle accident.

Toivari et al. Severity of Isolated Orbital Fractures in Geriatric Patients. J Oral Maxillofac Surg 2018.

$P=.032)$. A fracture area of $2 \mathrm{~cm}^{2}$ or greater was also significantly more frequent found among the elderly (43.1\%) than among the controls (31.1\%), although fissure fractures constituted $25.0 \%$ of the geriatric orbital fractures $(P=.045)$. Ocular injuries were only diagnosed in the geriatric group (5.6\%). These injuries included retrobulbar hematoma $(\mathrm{n}=2)$, retinal rupture $(n=1)$, and lens luxation $(n=1)$. Eight of the younger controls (13.8\%) and 11 of the geriatric study patients (15.2\%) were referred for ophthalmologic consultation.

The results of the logistic regression analyses between the type of orbital fracture, associated zone, and fracture area and age group are listed in Table 4. In the bivariate analyses, geriatric patients had a 2.2fold greater risk of fractures in the middle to posterior parts of the orbit (ie, zone 1 to 3, 2 and 3, or 3; $P=.033)$ and a 2.3 -fold greater risk of a fracture area of $2 \mathrm{~cm}^{2}$ or more $(P=.037)$. When adjusted for gender, trauma mechanism, alcohol abuse, and fracture type, the risk of fractures in zones 1 to 3,2 plus 3 , or 3 was 3.2-fold greater and the risk of fractures $2 \mathrm{~cm}^{2}$ or larger was 2.7-fold greater for the geriatric patients; however, the association was not statistically significant.

The amount of dislocation of orbital fractures and the fracture area for the geriatric and younger adult patients are listed in Table 5. The average dislocation of the isolated floor was $5.2 \mathrm{~mm}$ for both patient groups. In the isolated medial wall, the dislocation was on average $5.4 \mathrm{~mm}$ for the elderly and $4.6 \mathrm{~mm}$ for the controls. In the anteroposterior direction, the average dislocation was greater for fractures affecting the middle to posterior part or all orbital thirds (ie, zones 2 and 3, 1 to 3, or 3 ) in both the geriatric (average $5.3 \mathrm{~mm}$ ) and control (average $5.6 \mathrm{~mm}$ ) groups. On average, the fracture area of the orbital fractures was more extensive in the

\section{Table 2. ASSOCIATIONS BETWEEN GENDER, TRAUMA MECHANISM, AND ALCOHOL ABUSE AND ORBITAL FRACTURE} TYPE

Orbital Fracture Type

\begin{tabular}{|c|c|c|c|c|c|}
\hline Variable & Isolated Floor & Isolated Medial Wall & Combined $^{*}$ & Other $^{\dagger}$ & $P$ Value \\
\hline Population (n) & 84 & 14 & 26 & 7 & NA \\
\hline Gender & & & & & .139 \\
\hline Female & $49(72.1)$ & $6(8.8)$ & $9(13.2)$ & $5(7.4)$ & \\
\hline Male & $35(56.5)$ & $7(11.3)$ & $17(27.4)$ & $2(3.2)$ & \\
\hline Trauma mechanism & & & & & .049 \\
\hline Fall on ground & $39(65.0)$ & $5(8.3)$ & $14(23.3)$ & $2(3.3)$ & \\
\hline Unknown & $4(80.0)$ & $1(20.0)$ & $0(0.0)$ & $0(0.0)$ & \\
\hline MVA & $6(75.0)$ & $1(12.5)$ & $0(0.0)$ & $1(12.5)$ & \\
\hline Assault & $28(66.7)$ & $4(9.5)$ & $10(23.8)$ & $0(0.0)$ & \\
\hline Bicycle & $2(40.0)$ & $0(0.0)$ & $1(20.0)$ & $2(40.0)$ & \\
\hline Fall from height & $2(40.0)$ & $1(20.0)$ & $0(0.0)$ & $2(40.0)$ & \\
\hline Hit by blunt object & $1(100.0)$ & $0(0.0)$ & $0(0.0)$ & $0(0.0)$ & \\
\hline Sport & $2(50.0)$ & $1(25.0)$ & $1(25.0)$ & $0(0.0)$ & \\
\hline Alcohol abuse & $21(63.6)$ & $4(12.1)$ & $7(21.2)$ & $1(3.0)$ & .949 \\
\hline
\end{tabular}

Abbreviations: MVA, motor vehicle accident; NA, not applicable.

* Combined fracture of the floor plus medial or lateral wall, medial plus lateral wall, floor plus medial wall plus roof.

$\dagger$ Isolated fracture of the orbital roof or lateral wall. 
Table 3. ASSOCIATIONS BETWEEN AGE GROUPS AND RADIOLOGIC AND CLINICAL OUTCOMES

\begin{tabular}{|c|c|c|c|}
\hline Variable & Geriatric Patients $(n=72)$ & Younger Controls $(n=58)$ & $P$ Value \\
\hline Type of orbital fracture & & & .253 \\
\hline Isolated floor & $48(66.7)$ & $36(62.1)$ & \\
\hline Isolated medial & $5(6.9)$ & $9(15.5)$ & \\
\hline Combined* & $15(20.8)$ & $11(19.0)$ & \\
\hline Other $^{\dagger}$ & $4(5.6)$ & $2(3.4)$ & \\
\hline Associated zone & & & .032 \\
\hline Zone 1,2 , or 1 and 2 & $26(36.1)$ & $31(53.4)$ & \\
\hline Zone 2 and 3,1 to 3 , or 3 & $46(63.9)$ & $27(46.6)$ & \\
\hline Fracture area & & & .045 \\
\hline Fissure & $18(25.0)$ & $9(15.5)$ & \\
\hline$\leq 2 \mathrm{~cm}^{2}$ (no fissure) & $23(31.9)$ & $31(53.4)$ & \\
\hline$\geq 2 \mathrm{~cm}^{2}$ & $31(43.1)$ & $18(31.1)$ & \\
\hline Dislocation & & & .185 \\
\hline Yes & $54(75.0)$ & $49(84.5)$ & \\
\hline One wall & $46(63.9)$ & $43(74.1)$ & \\
\hline Two walls & $8(11.1)$ & $6(10.3)$ & \\
\hline Involvement of relevant clinical landmarks & & & .665 \\
\hline Posterior ledge & $6(8.3)$ & $9(15.5)$ & \\
\hline Intraorbital buttress & $3(4.2)$ & $3(5.2)$ & \\
\hline Inferior orbital fissure & $1(1.4)$ & $0(0.0)$ & \\
\hline Combination $^{\ddagger}$ & $4(5.5)$ & $3(5.2)$ & \\
\hline Post-traumatic binocular diplopia & $15(20.8)$ & $10(17.2)$ & .605 \\
\hline Primary altered ocular position & & & .437 \\
\hline Yes & $15(20.8)$ & $9(15.5)$ & \\
\hline Enophthalmos & $9(12.5)$ & $8(13.8)$ & \\
\hline Exophthalmos & $6(8.3)$ & $1(1.7)$ & \\
\hline Restricted eye movement & $6(8.3)$ & $4(6.9)$ & .760 \\
\hline Severe ocular injury & & & .068 \\
\hline Yes & $4(5.6)$ & $0(0.0)$ & \\
\hline Retrobulbar hematoma & $2(2.8)$ & $0(0.0)$ & \\
\hline Retinal rupture/detachment & $1(1.4)$ & $0(0.0)$ & \\
\hline Lens luxation & $1(1.4)$ & $0(0.0)$ & \\
\hline
\end{tabular}

* Combined fracture of the floor plus medial or lateral wall, medial plus lateral wall, floor plus medial wall plus roof. $\dagger$ Isolated fracture of the orbital roof or lateral wall.

$\ddagger$ Posterior ledge plus intraorbital buttress $(\mathrm{n}=3)$, and posterior ledge plus inferior orbital fissure $(\mathrm{n}=1)$.

Toivari et al. Severity of Isolated Orbital Fractures in Geriatric Patients. J Oral Maxillofac Surg 2018.

geriatric group with isolated fractures of the floor and medial wall and for combined fractures, with the largest difference in the combined orbital fractures $\left(1.0 \mathrm{~cm}^{2}\right.$, range 0.4 to 3.6 ). In relation to the orbital thirds, fractures affecting zones 2 and 3,1 to 3 , or 3 were $0.5 \mathrm{~cm}^{2}$ (range 0.2 to 3.6 ) larger on average in the geriatric patients than in the control group.

\section{Discussion}

The purpose of the present study was to investigate the differences in isolated orbital fractures between geriatric (age 65 years or older) and younger adult (age 20 to 50 years) patients. Our specific aims were to design and implement a case-control study to clarify the reasons for, types of, and degree of involvement of the orbital wall and the severity of isolated orbital frac- tures in geriatric patients and to compare the clinical and radiologic characteristics of elderly patients and younger controls. The hypotheses were that age and age-related mechanisms would predispose to different types of radiologic findings in orbital fractures and that ocular injuries would be more common among the elderly.

Our hypotheses were confirmed. The geriatric patients sustained isolated orbital fractures significantly more often because of falls $(P>.001)$, the orbital fractures were significantly more often more extensive (fracture area $2 \mathrm{~cm}^{2}$ or more; $P=.045$ ), and the fracture was located significantly more often behind the equatorial of the eye ball $(P=.032)$. The risk analyses showed that the risk was significantly elevated for fractures affecting the middle to posterior orbital thirds $(P=.033)$ and for extensive orbital fractures 
Table 4. LOGISTIC REGRESSION ANALYSES BETWEEN TYPES OF ORBITAL FRACTURE, ASSOCIATED ZONE, FRACTURE AREA, AND AGE GROUP

\begin{tabular}{|c|c|c|c|c|}
\hline \multirow[b]{2}{*}{ Variable } & \multirow{2}{*}{$\begin{array}{l}\text { Orbital Fracture Type } \\
\text { (Isolated Floor) }\end{array}$} & \multirow{2}{*}{$\begin{array}{c}\text { Associated Zone } \\
\text { (Zone } 1 \text { to } 3,2 \text { and } 3 \text {, or 3) }\end{array}$} & \multicolumn{2}{|c|}{ Fracture Area } \\
\hline & & & $\geq 2 \mathrm{~cm}^{2}$ (A) & $\geq 2 \mathrm{~cm}^{2}(\mathrm{~B})$ \\
\hline \multicolumn{5}{|l|}{ Unadjusted } \\
\hline Geriatric patients & $1.2(0.6-2.5)$ & $2.2(1.1-4.4)$ & $1.6(0.8-3.5)$ & $2.3(1.1-5.1)$ \\
\hline Younger controls & Reference & Reference & Reference & Reference \\
\hline$P$ value & .586 & .033 & .161 & .037 \\
\hline \multicolumn{5}{|l|}{ Adjusted* } \\
\hline Geriatric patients & $1.5(0.5-4.9)$ & $3.2(0.9-11.8)$ & $1.7(0.5-6.6)$ & $2.7(0.6-12.3)$ \\
\hline Younger controls & Reference & Reference & Reference & Reference \\
\hline$P$ value & .506 & .082 & .415 & .198 \\
\hline
\end{tabular}

Data presented as odds ratios ( $95 \%$ confidence intervals).

Abbreviations: A, compared with fissures and $\leq 2 \mathrm{~cm}^{2}$ fractures $(\mathrm{n}=130)$; $\mathrm{B}$, compared with $\leq 2 \mathrm{~cm}^{2}$ fractures $(\mathrm{n}=103)$.

* Adjusted for gender, trauma mechanism, alcohol abuse, and fracture type (except for orbital fracture type).

Toivari et al. Severity of Isolated Orbital Fractures in Geriatric Patients. J Oral Maxillofac Surg 2018.

$(P=.037)$ among the elderly patients. Moreover, the frequency of ocular injuries was greater among the elderly (5.6\%) than among the controls (0.0\%), although the difference was not statistically significant $(P=.068)$.

In the present study, the orbital floor was significantly the most common site of fracture for both geriatric (66.7\%) and control (61.2\%) patients $(P=.0253)$. Despite the similar division of fractured walls, geriatric patients had sustained more extensive fractures (fracture area $2 \mathrm{~cm}^{2}$ or more) significantly more often. Also, fractures in the elderly affected the middle to posterior thirds of the orbital wall (zones 2 and 3, 1 to 3 , or 3 ; ie, the area posterior to the globe equatorial, in which fractures are more likely to cause a change in the ocular position and post-traumatic enophthalmos) significantly more often $(P=.033) .{ }^{12}$ In more detailed radiologic analyses, the fractures affecting zones 2 and 3, 1 to 3, or 3 were $0.4 \mathrm{~cm}^{2}$ larger among the elderly, although the fracture area was similar between the 2 groups for fractures only affecting zones 1,2 , or 1 and 2 (ie, the anterior to middle orbital thirds). When comparing the fracture area according to the type of isolated orbital fracture, the average difference was greatest $\left(1 \mathrm{~cm}^{2}\right)$ for combined orbital fractures in the elderly. A study by Zimmerer et $\mathrm{al}^{11}$ demonstrated that, especially in orbital floor fractures, the injury was most commonly diagnosed in the middle (92.8\%) or posterior (54.9\%) third in the anteroposterior direction. The present results have shown that geriatric patients, in particular, have a greater risk and probability of sustaining extensive and posteriorly located orbital fractures.

Moreover, the fracture area, amount of displacement of orbital soft tissues to the paranasal sinuses, and loss of orbital ligament support are factors that allow for globe movement backward and downward. Regarding the displacement and volume change, a
5\% orbital volume change has been previously reported to be clinically relevant for the occurrence of post-traumatic enophthalmos. ${ }^{14}$ The results of our study suggest that geriatric orbital fractures were

\begin{tabular}{|c|c|c|}
\hline Variable & $\begin{array}{l}\text { Geriatric } \\
\text { Patients }\end{array}$ & $\begin{array}{l}\text { Younger } \\
\text { Controls }\end{array}$ \\
\hline \multicolumn{3}{|l|}{$\begin{array}{l}\text { Dislocation vs orbital } \\
\text { fracture type }(\mathrm{mm})\end{array}$} \\
\hline Isolated floor & $5.2(1.2-11.3)$ & $5.2(1.6-10.8)$ \\
\hline Isolated medial wall & $5.4(4.1-7.8)$ & $4.6(1.8-8.6)$ \\
\hline Combined ${ }^{*}$ & $4.8(1.6-9.5)$ & $4.7(1.5-8.1)$ \\
\hline Other ${ }^{\dagger}$ & $2.3(2.0-2.6)$ & 4.1 (NA) \\
\hline \multicolumn{3}{|l|}{$\begin{array}{l}\text { Dislocation vs associated } \\
\text { zone }(\mathrm{mm})\end{array}$} \\
\hline Zone 1,2 , or 1 and 2 & $3.7(1.2-9.0)$ & $4.2(1.6-8.6)$ \\
\hline $\begin{array}{l}\text { Zone } 2 \text { and } 3,1 \text { to } 3 \text {, } \\
\text { or } 3\end{array}$ & $5.3(1.6-11.3)$ & $5.6(1.5-10.8)$ \\
\hline \multicolumn{3}{|l|}{$\begin{array}{l}\text { Fracture area vs orbital } \\
\text { fracture type }\left(\mathrm{cm}^{2}\right)\end{array}$} \\
\hline Isolated floor & $2.1(0.4-3.8)$ & $1.99(0.5-3.4)$ \\
\hline Isolated medial wall & $1.1(0.3-2.0)$ & $0.8(0.2-1.4)$ \\
\hline Combined* & $3.9(0.6-8.0)$ & $2.9(1.0-5.6)$ \\
\hline Other $^{\dagger}$ & $1.0(0.9-1.1)$ & 3.7 (NA) \\
\hline \multicolumn{3}{|l|}{$\begin{array}{l}\text { Fracture area vs associated } \\
\text { zone }\left(\mathrm{cm}^{2}\right)\end{array}$} \\
\hline Zone 1,2 , or 1 and 2 & $1.6(0.3-2.5)$ & $1.6(0.2-3.7)$ \\
\hline $\begin{array}{l}\text { Zone } 2 \text { and } 3,1 \text { to } 3 \text {, } \\
\quad \text { or } 3\end{array}$ & $2.7(0.4-8.0)$ & $2.3(0.6-5.6)$ \\
\hline
\end{tabular}

Data presented as average (range).

* Combined fracture of the floor plus medial or lateral wall, medial plus lateral wall, floor plus medial wall plus roof.

$\dagger$ Isolated fracture of the orbital roof or lateral wall.

Toivari et al. Severity of Isolated Orbital Fractures in Geriatric Patients. J Oral Maxillofac Surg 2018. 
significantly more extensive, and the rate of dislocation revealed a maximal difference of $0.5 \mathrm{~mm}$ or less relative to the control group in the anteroposterior direction. However, the clinical parameters (presence of diplopia, clinically diagnosed altered ocular position, clinically restricted eye movements, or ocular injuries) did not differ significantly between the 2 groups. In the present results, immediate enophthalmos was more frequent among the younger adult (13.8\%) than the among the geriatric (12.5\%) patients. In contrast, the rate of immediate exophthalmos was clearly more frequent among the elderly (8.3\%) than among the controls (1.8\%). The incidence of posttraumatic binocular diplopia and the rate of restricted eye movements were greater among the geriatric patients (20.8 and $8.3 \%$, respectively) than among the controls (17.2 and $6.9 \%$, respectively). Immediate enophthalmos has traditionally been used as an indicator of massive fractures and soft tissue prolapse to the paranasal sinuses; however, post-traumatic edema can mask primary enophthalmos. ${ }^{17}$ The present results have shown that the presence of primary enophthalmos would not be a reliable indicator of an extensive fracture among geriatric patients, and, in contrast, the elderly appeared more prone to sustaining edema-related exophthalmos and restricted eye movements. Clinicians should give particular attention to the follow-up of geriatric orbital trauma, because, as shown by Catone et al, ${ }^{18}$ up to $10 \%$ of nonoperative orbital fracture patients experience enophthalmos that was masked by the primary edema.

Orbital fractures were caused by blunt mechanisms in the present study. The great majority of isolated orbital fractures were caused by falls in the geriatric group and assault in the control group $(P<.001)$. The most common type of fracture was an isolated fracture of the orbital floor for both etiologies $(P=.049)$. However, the risk of the geriatric patients sustaining extensive $\left(2 \mathrm{~cm}^{2}\right.$ or greater) fractures was 2.3 -fold greater than that of the younger controls compared with nonfissure fractures of $2 \mathrm{~cm}^{2}$ or less. Studies focusing on orthopedic injuries have demonstrated that intracortical porosity ${ }^{19}$ and decreased periosteal apposition ${ }^{20}$ cause bone fragility. More recently, a study by Lee et $\mathrm{al}^{21}$ revealed that the density of facial bones, in particular, in the midfacial area, including the orbital floor, is affected by osteoporosis. They emphasized that the decreased midfacial bone density, in particular, the porosity of the cortical bone, such as the orbital wall, and changes in periosteal support and tissue flexibility could be factors explaining the degree of involvement of the orbital wall in geriatric orbital fractures. In addition, it remains to be considered whether the trauma energy in elderly falls is equal to that in younger adult interpersonal violence (ie, when hit by a fist).
The present results have confirmed the findings of a Korean population-based study that $43.8 \%$ of the elderly had sustained orbital fractures due to falls, ${ }^{6}$ although the frequency of such fractures in the present study was clearly greater (79.2\%). Poor coordination, protracted reactivity, eyesight deterioration, their general condition, and greater use of medications are age-related factors that predispose the elderly to falls. In the present results, trauma-associated abuse of alcohol was significantly more frequent among the control group than among the geriatric group $(P=.003)$. However, of the coordination-affecting factors, the involvement of alcohol in $15.3 \%$ of cases in the elderly was nevertheless notable, and, in our experience, appears to be one of the predisposing factors for elderly falls in this particular cohort.

Even more important than the bony injury to the orbit, the evaluation of ocular injuries and vision should be the primary concern when evaluating orbital trauma. The frequency of associated ocular injuries has been reported to range from 22 to $30 \%$, with most ocular injuries characterized as self-limiting and minor. ${ }^{5,9,15,16}$ In the present results, ocular injuries were only found in the elderly patients (5.6\%). The rate was rather low compared with the results from Andrews et $\mathrm{al}^{15}$ or Ho et al. ${ }^{16}$ These investigators concluded that 10.0 to $26.7 \%$ of orbital fractures will include vision-threatening ocular injuries. ${ }^{15,16}$ One reason for our lower rate of ocular injuries might have been that during the study period, patients were referred for ophthalmologic consultation according to their symptoms. Another reason for the discrepancy in the results could be the differences in the study samples. In our study, only isolated orbital fractures were included; however, in the studies reported by Andrews et $\mathrm{al}^{15}$ and Ho et al ${ }^{16}$ that was not the only inclusion criterion. In the present results, all the eye injuries were diagnosed in the elderly population, although the proportion of patients referred for ophthalmologic consultation was $15.6 \%$ for the controls and $13.9 \%$ for the geriatric patients. The registered geriatric ocular injuries were all severe and threatened visual acuity (ie, retrobulbar hematoma [RBH], 50\%; retinal detachment, $25 \%$; and lens luxation, 25\%); these injuries were either RBH or posterior chamber injuries, as Andrews et al $^{15}$ also concluded. Ocular injuries related to isolated fractures of the floor (50\%) and combined fractures (50\%) were caused by falling (75\%) and assault (25\%).

The drawback of the present study was the lack of an ophthalmologic consultation for all the study patients. It would also have been interesting to compare the volume change between the study and control groups; however, we refrained from performing a volume evaluation owing to the potentially large error source in 3-dimensional volume evaluation from the 
archived CT images. However, the strength of the present study was the potential to show the differences between younger and elderly patients with isolated orbital fractures, which can also be evaluated in emergency centers without any particular volume calculation software.

In conclusion, falling was the most common mechanism for elderly orbital fractures. Isolated orbital fractures among geriatric patients were significantly more often extensive and mainly affected the globe supporting the middle and posterior part of the orbital wall. Clinicians should exclude ocular injuries that could reduce visual acuity in geriatric patients with orbital fractures.

\section{References}

1. Boffano P, Roccia F, Zavattero E, et al: European Maxillofacial Trauma (EURMAT project: A multicentre and prospective study. J Craniomaxillofac Surg 43:62, 2015

2. Smith H, Peek-Asa C, Nesheim D, et al: Etiology, diagnosis, and characteristics of facial fracture at a Midwestern level I trauma centre. J Trauma Nurs 19:57, 2012

3. Toivari M, Helenius M, Suominen AL, et al: Etiology of facial fractures in elderly Finns during 2006-2007. Oral Surg Oral Med Oral Pathol Oral Radiol 118:539, 2014

4. Atisha DM, Burr TV, Allori AC, et al: Facial fractures in the aging population. Plast Reconstr Surg 137:587, 2016

5. Cruz AA, Eichenberger GC: Epidemiology and management of orbital fractures. Curr Opin Ophthalmol 15:416, 2004

6. Kim YJ, Ahn S, Seo DW, et al: Patterns and injuries associated with orbital wall fractures in elderly patients who visited the emergency room: A retrospective case-control study. BMJ Open 19:6, 2016

7. Shere JL, Boole JR, Holtel MR, Amoroso PJ: An analysis of 3599 midfacial and 1141 orbital blowout fractures among 4426 United States Army Soldiers, 1980-2000. Otolaryngol Head Neck Surg 130:164, 2004
8. Burm J, Ching C, Oh S: Pure orbital blowout fracture: New concepts and importance of medial orbital blowout fracture. Plast Reconstr Surg 103:1839, 1999

9. Ellis E: Orbital trauma. Oral Maxillofac Surg Clin North Am 24: 629, 2012

10. He D, Blomquist PH, Ellis E III: Association between ocular injuries and internal orbital fractures. J Oral Maxillofac Surg 65 : 713, 2007

11. Zimmerer RM, Ellis E III, Aniceto GS, et al: A prospective multicenter study to compare the precision of posttraumatic internal orbital reconstruction with standard preformed and individualized orbital implants. J Craniomaxillofac Surg 44:1485, 2016

12. Zhang Z, Zhang Y, He Y, et al: Correlation between volume of herniated orbital contents and the amount of enophthalmos in orbital floor and wall fractures. J Oral Maxillofac Surg 70:68, 2012

13. Leatherbarrow B: Oculoplastic Surgery, Vol 2. Boca Raton, FL, CRC Press, 2010, pp 547-568

14. Manson PN: Facial fractures, in : Mathes SJ (ed): Plastic Surgery, Vol 3. Philadelphia, PA, Saunders Elsevier, 2006, pp 264-292

15. Andrews BT, Jackson AS, Nazir N, et al: Orbit fractures: Identifying patient factors indicating high risk for ocular and periocular injury. Laryngoscope 126(Suppl 4):S5, 2016

16. Ho TQ, Jupiter D, Tsai JH, Czerwinski M: The incidence of ocular injuries in isolated orbital fractures. Ann Plast Surg 78:59, 2017

17. Converse J: Editorial on the treatment of blow-out fracture of the orbit. Plast Reconstr Surg 62:100, 1978

18. Catone G, Morris M, Carlson E: A retrospective study of untreated orbital blow-out fractures. J Oral Maxillofac Surg 46: 1033,1988

19. Zebabe RM, Ghasem-Zadeh A, Bohte A, et al: Intracortical remodelling and porosity in the distal radius and post-mortem femurs of women: A cross-sectional study. Lancet 15:1729, 2010

20. Szulc P, Seeman E, Duboeuf F, et al: Bone fragility: Failure of periosteal apposition to compensate for increased endocortical resorption in postmenopausal women. J Bone Miner Res 21: 1856,2006

21. Lee IJ, Lee JJ, Bae JH, et al: Significance of osteoporosis in facial bone density using computed tomography. J Craniofac Surg 24: 428,2013 